\title{
Agbiotech and world food security - threat or boon?
}

\author{
Richard Gilmore
}

Lurking behind the debate on genetically modified organisms (GMOs) is the phantom fear of the ownership of staple food resources. Corporate control and US domination may, in fact, be the real boogeyman. Most assuredly, there continues to be a level of concern about the impact of scientific alteration of crops on our health and environment. But the world community is gradually building an infrastructure of biosafety to accommodate new agricultural technologies and products. Though not without its serious shortcomings, the protocol on biosafety drafted in Montreal in late January indicates that there is now an across-the-board consensus that at least recognizes the potential of biotechnology for food and agriculture.

Foreign ownership of food resources is an inflammatory issue when it comes to sovereign assertions of national independence and food security. Although global regulatory systems are grappling with ways to cope with this dilemma, recent corporate developments may have removed some of the sting from the dialogue. Prompted by poor performance in life science divisions, some of the GMO giants have either undergone or are in the process of undergoing restructuring. Although the process is still developing, a commercial climate is beginning to emerge that is more hospitable to diversification and a wider participation in developing bioactive agricultural resources.

Nonetheless, critics continue to cast GMOs as a threat to both organic and independent smaller farmers. With religious zeal, they advance the legacy of the romantic myth that the family farm is still the mainstay of modern agriculture and the most effective guardian of the world ecosystem. The visceral fear remains that GMOs are dominated by huge, integrated corporations whose interests are inimical to those of a competitive agricultural system.

There may be cause for concern regarding the level of integration between suppliers and processors and of concentration among input suppliers, but it need not rest on false or unrealistic notions about the role of traditional farming, particularly in developing countries. Indeed, a strong economic case can be made for the ills of monopoly in any sector. The problems become more worrisome if the oligopoly is also an oligopsony-

Richard Gilmore is CEO and president of GIC Group, 1016 Duke Street, Alexandria, VA 22314 (rickgilmore@gicgroup.com). in which the same few buyers are also the predominant sellers of GMO inputs.

There is little doubt that GMO technologies have ushered in a phase of vertical integration and coordination in the agricultural sector. The main reasons for this trend are the following: first, high capitalization requirements at the R\&D level; second, closely linked input-output farming to respond to targeted end-user requirements; third, farm consolidation in the Western Hemisphere and within the European Union; fourth, labeling and diverse national and international regulatory requirements; and fifth, an evolution toward global marketing strategies.

At the very least, expectations have been raised that there will be a prevailing trend toward contract farming where producers develop crops to conform to processor requirements. The degree to which growers fall in line will depend on how competitively priced the GMO inputs are and how much of a value-added premium the growers will appreciate in this high-tech form of production. With the consumer backlash in Europe, the time line for these changes to occur may be extended.

Biotechnologies have already resulted in increased corporate concentration in the seed and chemical industries, as demonstrated by a dazzling array of mergers. Whatever the commercial rationale in favor of these mergers, concern remains that their net effect will be to direct technologies to what may be commercially viable at the expense of more socially desirable technologies and products. GMO companies, for example, may forego certain pest resistance or nitrogen fixation options because of their potential infringement on the market of their flagship chemical and fertilizer products.

On the other hand, GMO giants may be losing some of their firepower over the short term, as witnessed by the likely decimation of Monsanto (St. Louis, MO), or Novartis' (Basel) self-induced weight reduction. These changes present new commercial opportunities. Similarly, the maturation of recombinant technologies is introducing consumers to product choices they never previously had. GMO companies once associated with soybean and corn production have now graduated to offering nutraceutical products grown under controlled and systematic conditions, and wide-ranging foods targeted to special diets and taste preferences.

There are other positive signs that counter assumptions that the world will soon be facing a cartel for GMOs. First, profitable growers may assume a more important role in the world marketing system as integrated systems become more dependent on their inputs. Second, value-added product will increase the efficiency and return to growers worldwide. In 1996, a study by Falckk-Zepeda, Trazler, and Nelson ${ }^{1}$ found that the relative returns for Bacillus thuringiensis (Bt) cotton in 1997 were 42\% to US farmers, $44 \%$ to Monsanto/Delta \& Pine Land, and $7 \%$ to US consumers. In 1999, the same authors reported findings that "farmers and innovators share almost equally the rents created by adopting $B t$ cotton" 2 . They also found that regions such as California and Missouri, having low adoption rates, were disadvantaged because their "farmers suffered a price reduction of cotton lint without having the benefits of the technology" . Third, small and medium-sized companies continue to dominate biotechnology R\&D. Fourth, consumers are likely to have more market influence with GMOs than in the past, when a greater portion of production was in undifferentiated crops. Fifth and finally, the application of biotechnologies to agriculture will serve to create nontraditional linkages to other markets, including pharmaceuticals, animal health, chemicals, and a range of industrial markets not normally associated with agriculture.

Resistance to the wholesale adoption of GMOs has produced constructive results. Putting the brakes on indiscriminate commercialization while establishing an infrastructure for the enforcement of biosafety has introduced a greater appreciation of the shared gain in biotechnology. In recent years, European countries have actually stepped up their research in biotechnology applications for agriculture and Japan has not wavered in its commitment to the sector, despite their stringent regulatory regimes.

As with other watershed initiatives in economic history, the era of GMOs has ushered in a host of concerns, some more legitimate than others. There must be a concerted effort to anticipate and tackle the real probelms. With safeguards in place, GMOs offer tremendous promise for world agriculture.

\footnotetext{
1. Falck-Zepeda, J.B., Traxler, G., and Nelson, R.G. Rent Creation and Distribution from the First Three Years of Planting Bt Cotton. The International Service for the Acquisition of Agri-biotech Applications (ISAAA) Briefs No. 14 Ithaca, NY 14 (1999).

2. Ibid, p.v.

3. Ibid, p. 15.
} 